Article

\title{
Augmented Therapeutic Potential of Glutaminase Inhibitor CB839 in Glioblastoma Stem Cells Using Gold Nanoparticle Delivery
}

\author{
Beatriz Giesen $^{1}\left(\mathbb{D}\right.$, Ann-Christin Nickel ${ }^{2}$, Juri Barthel ${ }^{3} \mathbb{D}$, Ulf Dietrich Kahlert ${ }^{2,4, *(D)}$ and Christoph Janiak ${ }^{1, *}$ (D) \\ 1 Institut für Anorganische Chemie und Strukturchemie, Heinrich-Heine-Universität Düsseldorf, \\ 40204 Düsseldorf, Germany; beatriz.giesen@uni-duesseldorf.de \\ 2 Klinik für Neurochirurgie, Medizinische Fakultät, Universitätsklinikum Düsseldorf, \\ 40225 Düsseldorf, Germany; ann-christin.nickel@med.uni-duesseldorf.de \\ 3 Ernst Ruska-Centrum für Mikroskopie und Spektroskopie mit Elektronen (ER-C 2), Forschungszentrum \\ Jülich GmbH, 52425 Jülich, Germany; ju.barthel@fz-juelich.de \\ 4 Deutsches Konsortium für Translationale Krebsforschung (DKTK), 40225 Düsseldorf, Germany \\ * Correspondence: ulf.kahlert@med.uni-duesseldorf.de (U.D.K.); janiak@uni-duesseldorf.de (C.J.)
}

Citation: Giesen, B.; Nickel, A.-C.; Barthel, J.; Kahlert, U.D.; Janiak, C. Augmented Therapeutic Potential of Glutaminase Inhibitor CB839 in Glioblastoma Stem Cells Using Gold Nanoparticle Delivery. Pharmaceutics 2021, 13, 295. https://doi.org/ 10.3390/ pharmaceutics13020295

Academic Editor: Sabrina Pricl

Received: 25 January 2021

Accepted: 18 February 2021

Published: 23 February 2021

Publisher's Note: MDPI stays neutral with regard to jurisdictional claims in published maps and institutional affiliations.

Copyright: (c) 2021 by the authors. Licensee MDPI, Basel, Switzerland. This article is an open access article distributed under the terms and conditions of the Creative Commons Attribution (CC BY) license (https:/ / creativecommons.org/licenses/by/ $4.0 /)$.

\begin{abstract}
Gold nanoparticles (Au NPs) are studied as delivery systems to enhance the effect of the glutaminase1 inhibitor CB839, a promising drug candidate already in clinical trials for tumor treatments. Au NPs were synthesized using a bottom-up approach and covered with polymers able to bind CB839 as a Au-polymer-CB839 conjugate. The drug loading efficiency (DLE) was determined using high-performance liquid chromatography and characterization of the CB839-loaded NPs was done with various microscopic and spectroscopic methods. Despite the chemical inertness of CB839, $\mathrm{Au}$ NPs were efficient carriers with a DLE of up to $12 \%$, depending on the polymer used. The therapeutic effect of CB839 with and without Au was assessed in vitro in 2D and 3D glioblastoma (GBM) cell models using different assays based on the colony formation ability of GBM stem cells (GSCs). To avoid readout disturbances from the Au metal, viability methods which do not require optical detection were hereby optimized. These showed that Au NP delivery increased the efficacy of CB839 in GSCs, compared to CB839 alone. Fluorescent microscopy proved successful NP penetration into the GSCs. With this first attempt to combine CB839 with Au nanotechnology, we hope to overcome delivery hurdles of this pharmacotherapy and increase bioavailability in target sites.
\end{abstract}

Keywords: glutaminase inhibition; gold nanoparticles; drug delivery; glioblastoma stem cells

\section{Introduction}

The low survival rate of patients after diagnosis with glioblastoma (GBM), a highly aggressive brain cancer, is believed to rely on the invasive nature of the tumor, its innate recurrence and the high level of therapy resistance of the disease [1]. Moreover, the difficulty of therapeutics to sufficiently pass the blood-brain barrier (BBB) during treatment adds to the complexity of the management of patients with GBM [2,3]. A subpopulation of cells with enhanced stem characteristics (GBM stem-like cells, GSCs) have been the focus of new strategies to eradicate GBM, as they seem to be responsible for building therapy resistance due to their self-renewal properties and their ability to differentiate into a variety of cell types within the tumor [4-6].

In recent years, the increased glucose and glutamine uptake of tumors needed to maintain their metabolism has been exploited as a target in breast, prostate, glioma, lung, kidney, thyroid, and blood cancers [7-13]. Instead of converting glucose to pyruvate to produce adenosine triphosphate (ATP) like normal cells, cancer cells have been known to utilize glutamine, an amino acid contained abundantly in plasma, as a nitrogen and carbon source to synthesize ATP and nucleotides [14]. During glutaminolysis, glutamine is hydrolyzed to glutamate and ammonia by the mitochondrial enzyme glutaminase1 (GLS1), 
a process needed to produce substrates for the citric acid cycle and subsequently supply the cells with vital proteins and other important metabolites [15]. Thus, by inhibiting the function of glutaminases, cell apoptosis and a slower tumor growth is expected and has already been observed in a variety of cases [16].

The compound $\mathrm{N}$-[5-[4-[6-[[2-[3-(trifluoromethoxy)phenyl]-acetyl]amino]-3-pyridazinyl] butyl]-1,3,4-thiadiazol-2-yl]-2-pyridineacetamide (CB839) (Figure 1) shows great promise as a glutaminase inhibitor, with several clinical trials as cancer therapy underway $[17,18]$. Most recently, CB839-brand marked under the name Telaglenastat-is being investigated in a phase 2 , randomized, multicenter, double-blind clinical study enrolling 120 lung cancer patients (NCT04265534). Treatment regime consists of orally administered CB839 as a supplement to food. Moreover, the tolerability of the drug in healthy adults dosing $800 \mathrm{mg}(4 \times 200 \mathrm{mg}$ tablets) administered twice daily is currently being assessed in the phase 1 NCT04607512 trial.

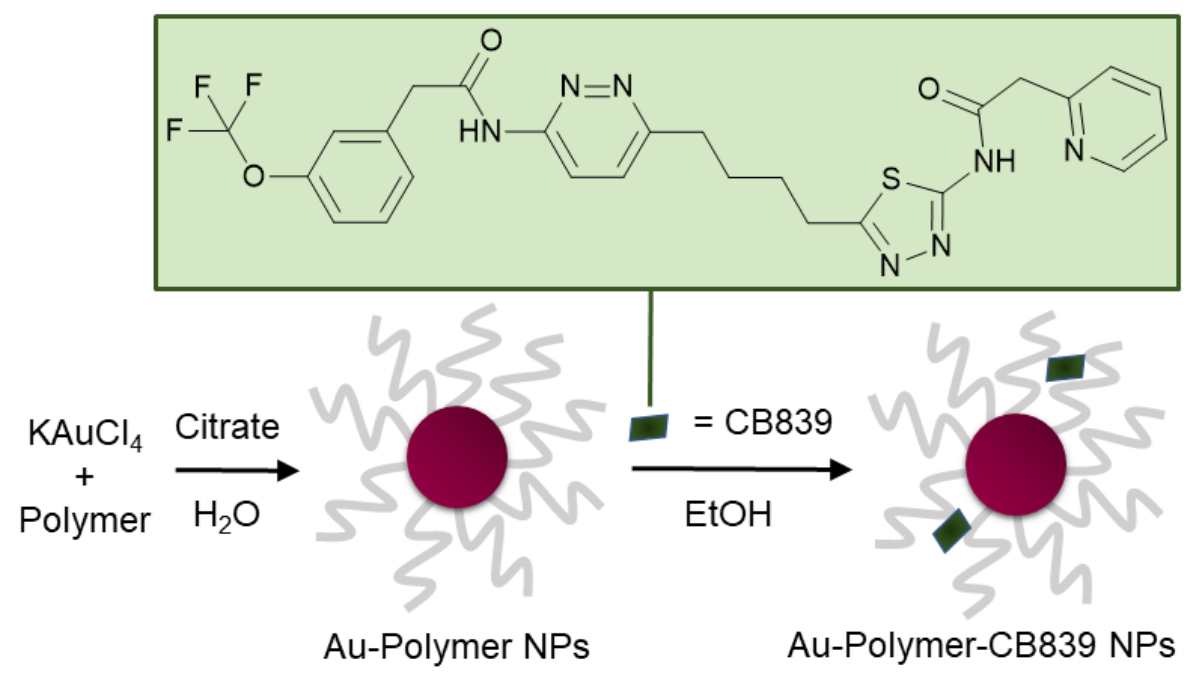

Figure 1. Schematic synthesis of polymer coated gold nanoparticles (Au NPs) carrying the CB839 inhibitor.

CB839 has good oral bioavailability and a potency independent from glutamine concentration about 13 times higher than its predecessor bis-2-(5-phenylacetamido-1,3,4thia-diazol-2-yl)ethyl sulfide (BPTES) [19]. We and others have previously shown that pharmacological GLS inhibition (GLSi) is effective to combat GSCs $[20,21]$ and GLSi candidate CB839 is the favorable strategy to do so, as it has superior target specificity [22]. In vivo therapy studies with this drug candidate, however, have shown that-in comparison to other tissues-the brain accumulation of CB839 is significantly hindered, most likely due to the challenge of passing the BBB [19]. Moreover, this in vivo trail enforces improving the general bioavailability of CB839 into the tumor sites, as oral treatment with the compound require severely high dosages to achieve therapy efficacy. Thus, new strategies to ensure more effective penetration of this promising drug candidate into tumor cells are urgently required.

The use of gold nanoparticles (Au NPs) as therapy carrier platform surges in recent biomedical applications due to their straight-forward synthesis and various, modifiable intrinsic functional properties [23]. Furthermore, nanoparticles present an enhanced permeation and retention (EPR) effect in tumors and can successfully transverse the cell membrane barrier of GSCs, as previously demonstrated [24,25]. In addition, Au NPs as pharmacological carriers can be beneficial to overcome the obstacles of administrating poorly water-soluble compounds such as CB839, thereby reducing the required doses to be administered and possibly minimizing risks of side-effects in patients.

Unlike prior glutaminase inhibitors, new generation inhibitors such as BPTES or BPTES analogues like CB839 do not contain highly reactive functional groups in their structure [26]. While this is considered a biological advantage because the drug cannot form toxic intermediates with proteins, it complicates a possible binding to the surface of a NP. 
Because no covalent bonds can be easily formed between CB839 and NP capping ligands, the use of conventional drug-attachment methods such as click-reactions, 1-ethyl-3-(3dimethylaminopropyl) carbodiimide hydrochloride/N-hydroxy succinimide (EDC/NHS) chemistry and cross-linkers (as seen for doxorubicin or anticancer taxanes such as paclitaxel or docetaxel) [27-29] is not possible without significant structure modification. Since such an alteration poses a high risk to influence the promising clinical effect known for this inhibitor, choosing a polymer as a surface ligand can provide the necessary matrix to load the CB839 molecules to the NPs. Through physical adsorption, polymers are capable of easily embedding drugs and macromolecules without the need for chemical modification, sometimes even achieving a higher loading than encapsulation techniques [30]. Moreover, polymers can increase the retention time of drugs, as well as their circulation in blood and are able to release them when the conjugate is exposed to endo- and exogeneous tumor stimuli [31].

In this work, a variety of biocompatible polymers were extensively examined regarding their ability to load CB839 onto the surface of the polymer-coated Au NPs (Figure S1, Supplementary Materials). After a fast preparation of Au-Polymer-CB839 NPs without the need of additional linkers (Figure 1), the efficacy of the CB839 inhibitor with and without the Au carriers was assessed in vitro using GBM neurospheres. These neurospheres are capable of reflecting the original tumor environment more closely due to their threedimensional structure, compared to classical disease models using monolayer culturing technology [32]. For example, a hypoxic micro-environment could be formed in spheres from the outside to the inner core or the drug uptake can be slower for the inner cells than for the outlaying cells [33]. Since the low toxicity of the individual components of the conjugate (Au NPs, polymers and CB839 on non-tumor cells) is well known [22,34-36], we focused on the synthesis of novel Au-Polymer-CB839 NPs and the assessment of its therapeutic potential compared to the neat counterpart. Our results advocate Au NPs to effectively improve the therapeutic potential of anti-tumor metabolic therapies.

To our knowledge, CB839 has only been combined with purely polymeric NPs and liposomes to facilitate its administration $[37,38]$ but this is the first time it is attached to $\mathrm{Au}$ NPs. Contrary to commonly used assays such as MTT, Cell-Titer-Glo ${ }^{\circledR}$ or Annexin A5, our focus lied further in the optimization of methods to assess the viability of the GSCs after treatment with Au-Polymer-CB839 NPs that do not rely on optical detection or addition of reagents. Au NPs may disturb assay readouts through their ability to absorb visible light, lumines, quench fluorescent signals or simply by interacting with assay components [39-41]. Thus, it is of high importance to have reliable and easy-to-apply methods to test the toxicity of drugs when using Au NPs.

\section{Materials and Methods}

\subsection{Materials}

Potassium tetrachloridoaurate (III), polyvinyl alcohol (PVA) Mowiol 4-88, $M_{w} \sim 31,000$ $\mathrm{g} / \mathrm{mol}$, poly(ethylene glycol) methyl ether thiol (ThioPEG), $M_{w} \sim 800 \mathrm{~g} / \mathrm{mol}$, branched polyethylene imine (PEI) $M_{w} \sim 25,000 \mathrm{~g} / \mathrm{mol}$, polyvinyl pyrrolidone (PVP), $M_{w} \sim 3500 \mathrm{~g} / \mathrm{mol}$, fluorescein isothiocyanate (FITC), crystal violet, 4-nitro blue tetrazolium chloride, 4',6diamidino-2-phenyl-indol-dihydro-chloride (DAPI), Trypan Blue and Heparin (\#H0878) were purchased from Sigma Aldrich, Darmstadt, Germany. Sodium citrate dihydrate was from J.T. Baker Chemicals, Schwerte, Germany and dimethyl sulfoxide (DMSO, 99.7\% purity) from Honeywell, Offenbach, Germany. Telaglenastat (CB839) was purchased from Adooq Bioscience, Irvine, CA, USA. Ethanol and methanol (Merck, Darmstadt, Germany) were of p.a. purity. Penicillin/Streptomycin (\#P4333) was also from Merck, Darmstadt, Germany. Phosphate-buffered saline (PBS, Gibco \#10010015), Dulbecco's Modified Eagle Medium without pyruvate (DMEM, Gibco \#11965092), B27 supplement (Gibco \#17504044), Ham's F12 Nutrient Mix (Gibco \#11765047), Antibiotic-Antimycotic (Gibco \#15240096), fetal bovine serum (FBS, Gibco \#11965092), poly-D-lysine (Gibco \#A3890401), agarose (Gibco \#18300012) and slide mounting solution (eBioscience ${ }^{\mathrm{TM}}$ Fluoromount- $\mathrm{G}^{\mathrm{TM}}$, \#00-4958-02) 
were from Thermo Fisher Scientific, Schwerte, Germany. Human epidermal growth factor (\#AF-100-15) and human basic fibroblast growth factor (\#AF-100-18B) were from Peprotech, Rocky Hill, NJ, USA and the tissue medium (\#1620C) from KliniPath, Duiven, Netherlands. The Spectra/Por ${ }^{\circledR}$ dialysis membrane was purchased from Spectrum Laboratories, Schwerte, Germany. All materials were used without further purification. The Milli- $\mathrm{Q}^{\circledR}$ purification system was used to treat water for all reactions.

\subsection{Methods}

Transmission electron microscopy (TEM): $10 \mu \mathrm{L}$ of each gold solution (in water for AuCit, AuThioPEG, AuPVP, AuPVA, and AuPEI; in ethanol for AuR-CB839 NPs) were dropped without dilution onto a $200 \mu \mathrm{m}$ carbon-coated copper grid (from Electron Microscopy Sciences \#CF200-CU, Munich, Germany), followed by drying in air. An FEI Tecnai G2 F20 electron microscope [42] operated at $200 \mathrm{kV}$ accelerating voltage was used and TEM images were recorded with a Gatan UltraScan 1000P camera. Image calibration was done using Debye-Scherrer patterns recorded from a gold reference sample (S106, Plano GmbH, Wetzlar, Germany). To determine the NP size and size distribution, over 100 particles were counted using the Gatan Digital Micrograph software.

Scanning transmission electron microscopy (STEM) measurements were carried out using a high-angle annular dark-field (HAADF) detector combined with energy-dispersive X-ray (EDX) mapping. The sample preparation was the same as for TEM.

Fourier transform infrared (IR) spectra were recorded on a Bruker TENSOR 37 spectrometer in attenuated total reflection mode (Platinum ATR-QL, Diamond) between 550$4000 \mathrm{~cm}^{-1}$ after solvent removal from purified gold samples.

Ultraviolet-visible (UV-VIS) spectra were measured on a UV-2450 spectrometer (Shimadzu, Kyoto, Japan) using gold solutions and further analysis was done using the UVProbe software (Shimadzu).

Fluorescence spectroscopy: Gold solutions were diluted 1:10 in PBS, placed in quartz glass cuvettes and analyzed with an excitation of $490 \mathrm{~nm}$ on a FluoroMax- 4 Spectrofluorometer from HORIBA Scientific, Irvine, CA, USA.

Thermogravimetric analysis (TGA) was carried out after solvent removal from purified gold samples on a Netzsch TG209 F3 Tarsus (Netzsch, Selb, Germany) under nitrogen atmosphere between 30 and $1000{ }^{\circ} \mathrm{C}$ at a heating rate of $5 \mathrm{~K} \mathrm{~min}^{-1}$.

Dynamic light scattering (DLS): Hydrodynamic diameters were determined with a Malvern Nano S Zetasizer instrument with a HeNe laser at a wavelength of $633 \mathrm{~nm}$ by diluting the ethanolic AuPVA-CB839 sample 1:20 in $\mathrm{H}_{2} \mathrm{O}$ or DMEM.

High-performance liquid chromatography (HPLC): Detection and quantification of CB839 in the supernatant samples was done using a Shimadzu LC 20AT prominence instrument with an SPD-M20A detector and a Luna C18(2) $(250 \times 4.60 \mathrm{~mm}, 5$ micron) column from Phenomenex ${ }^{\circledR}$. The sample loop volume was $20 \mu \mathrm{L}$ and the absorbance was detected at a wavelength of $254 \mathrm{~nm}$. The mobile phase consisted of $33 \%$ methanol and $67 \% \mathrm{H}_{2} \mathrm{O}$ with a flow rate of $1 \mathrm{~mL} / \mathrm{min}$. Before each measurement, the column was flushed with the $\mathrm{MeOH} / \mathrm{H}_{2} \mathrm{O}$ mixture for $30 \mathrm{~min}$. The total run time per measurement was $13 \mathrm{~min}$, whereas the CB839 peak could be found after approximately 9 min. Quantification of CB839 was done via peak integration after making a standard calibration curve.

\subsection{Nanoparticle Synthesis}

Citrate-coated gold nanoparticles (AuCit): $20 \mathrm{mg}(53 \mu \mathrm{mol})$ of $\mathrm{KAuCl}_{4}$ were dissolved in $200 \mathrm{~mL}$ of $\mathrm{H}_{2} \mathrm{O}$ and the solution was heated to $100{ }^{\circ} \mathrm{C}$ while stirring at $250 \mathrm{rpm}$. After addition of $93 \mathrm{mg}(319 \mu \mathrm{mol})$ of sodium citrate, the color changed to bright red. The AuCit NP suspension was washed with $200 \mathrm{~mL}$ of $\mathrm{H}_{2} \mathrm{O}$ using centrifugation $\left(22,000 \mathrm{rcf}, 1 \mathrm{~h}, 4{ }^{\circ} \mathrm{C}\right)$ and resuspended in $200 \mathrm{~mL}$ of water before reaction with PEG and PVP or in ethanol before loading with CB839.

ThioPEG-coated gold nanoparticles (AuThioPEG) and PVP-coated gold nanoparticles (AuPVP): The aqueous AuCit NP solution $(200 \mathrm{~mL})$ was reacted with ThioPEG or PVP in excess 
$(100 \mu \mathrm{mol})$ and stirred at room temperature for $24 \mathrm{~h}$. After separation via centrifugation, the polymer-coated Au NPs AuThioPEG and AuPVP were resuspended in $200 \mathrm{~mL}$ of ethanol. PVA-coated gold nanoparticles (AuPVA): $20 \mathrm{mg}(53 \mu \mathrm{mol})$ of $\mathrm{KAuCl}_{4}$ were added to a PVA solution ( $33 \mathrm{mg}$ in $200 \mathrm{~mL}$ of $\mathrm{H}_{2} \mathrm{O}$ ) and heated to $90^{\circ} \mathrm{C}$. When the temperature was reached, $29 \mathrm{mg}(100 \mu \mathrm{mol})$ of sodium citrate were added and the solution was continued to stir for 30 min until it turned dark red. After washing with $200 \mathrm{~mL}$ of water and centrifuging, the AuPVA NPs were resuspended in $200 \mathrm{~mL}$ of ethanol.

PEI-coated gold nanoparticles (AuPEI) were synthesized as described previously [25].

\subsection{Loading of CB839 to Gold Nanoparticles (AuR-CB839, R: Cit, ThioPEG, PVP, PVA, PEI)}

$50 \mathrm{~mL}$ of the ethanolic solutions of AuCit, AuThioPEG, AuPVP, AuPVA and AuPEI NPs were combined with a $1 \mathrm{~g} / \mathrm{L}$ CB839 stock in ethanol to obtain a final drug concentration of $0.05 \mathrm{~g} / \mathrm{L}$. The solutions were heated to $40{ }^{\circ} \mathrm{C}$ for $30 \mathrm{~min}$ and stirred for another $72 \mathrm{~h}$ at room temperature. After centrifugation for $1 \mathrm{~h}$ at 22,000 $\mathrm{rcf}$ and $4{ }^{\circ} \mathrm{C}$, the supernatants were collected and used to quantify the unloaded amount of the drug which remained in solution via HPLC. Using the HPLC values, the mass of CB839 in the NPs was calculated by subtracting the CB839 amount used from the amount found in the supernatants. For each batch, the AuR-CB839 NPs pellets were resuspended with a specific volume of DMEM so that in each AuR-CB839 NP dispersion the concentration of CB839 was equivalent to $1 \mu \mathrm{mol} / \mathrm{L}$. Since each NP type loaded different amounts of CB839 (see Section 3.2), the DMEM volume was adjusted depending on the sample. This procedure was repeated for each $50 \mathrm{~mL}$ NP batch synthesized, whereas HPLC results varied by about $1-6 \%$ between batches.

\subsection{Synthesis of Fluorescent PVA Gold Nanoparticles (AuPVA-FITC)}

FITC conjugated AuPVA nanoparticles were synthesized according to a two-step process based on our previously published reaction method [25]. In short, FITC was reacted with the pre-formed AuPVA NPs (synthesized as explained in Section 2.3). To increase the solubility of FITC, $50 \mathrm{mg}(0.13 \mathrm{mmol})$ of the solid were dissolved in DMSO to form a FITC DMSO solution with a concentration of $4 \mathrm{~g} / \mathrm{L}$. This DMSO solution was then diluted to $0.05 \mathrm{~g} / \mathrm{L}$ in water (FITC stock solution). Five milliliters of this stock solution were added to $50 \mathrm{~mL}$ of the aqueous AuPVA NP suspension, stirred at room temperature for $8 \mathrm{~h}$ and dialyzed through a $3.5 \mathrm{kDa}$ Spectra/Por ${ }^{\circledR}$ membrane against PBS for $24 \mathrm{~h}$. AuPVA-FITC NPs were washed with $50 \mathrm{~mL}$ of $\mathrm{H}_{2} \mathrm{O}$ and redispersed in $50 \mathrm{~mL}$ of DMEM.

\subsection{Cell Cultures}

JHH520 cells were provided by G. Riggins (Baltimore, MD, USA), GBM1 by A. Vescovi (Milan, Italy) and BTSC407 by M.S. Carro (Freiburg, Germany). GBM neurospheres were cultured in DMEM without pyruvate, 2\% B27 supplement, 30\% Ham's F12 Nutrient Mix, $20 \mathrm{ng} / \mathrm{mL}$ human epidermal growth factor, $20 \mathrm{ng} / \mathrm{mL}$ human basic fibroblast growth factor, $5 \mu \mathrm{g} / \mathrm{mL}$ heparin and antibiotic-antimycotic solution. U87 cells, kindly provided by A. Weyerbrock (University Freiburg, Freiburg, Germany), were cultured adherently in DMEM medium supplemented with 10\% FBS. All cells were cultured in the presence of $1 \%$ Penicillin/Streptomycin. The absence of mycoplasma contamination was tested for all cells and their genetic identity was validated using short tandem repeat analysis as previously published [43]. Ethical approval for the use of the cell models to study brain cancer biology was from the ethical commission of the medical faculty of Heinrich-Heine University (study ID 5841R, initial approval 31March 2017, revised and renewed 16 September 2019). For all the functional assays we applied the following treatment conditions: Volume adjusted media treatment (control); $1 \mu \mathrm{mol} / \mathrm{L} \mathrm{CB839}$ or Au NP suspension containing $1 \mu \mathrm{mol} / \mathrm{L}$ CB839. CB839 was dissolved in ethanol and for a $3 \mathrm{~mL}$ well, $1.7 \mu \mathrm{L}$ of this stock solution was added. We chose $1 \mu \mathrm{mol} / \mathrm{L}$ as our standard in vitro substance treatment condition as this concentration is generally considered sufficient to achieve a corresponding peak serum level in clinical testing [44]. Moreover, our group previously showed that this 
concentration of CB839 is a suitable parameter setting to conduct meaningful assays using the same preclinical models [22].

\subsection{Colony Formation Assays}

Poly-D-Lysine method: A solution of $0.1 \mathrm{~g} / \mathrm{L}$ of poly-D-lysine was diluted with sterile PBS to a concentration of $50 \mu \mathrm{g} / \mathrm{mL}$ and used to coat six-well flat-bottom plates. After $1 \mathrm{~h}$ of incubation at room temperature, the solution was removed and the plates were washed 3-times with sterile $\mathrm{H}_{2} \mathrm{O}$ and left to dry on a sterile bench for $2 \mathrm{~h}$. Subsequently, 500 suspension cells (GSCs) were seeded successfully attaching completely within $24 \mathrm{~h}$. After that, the culture medium was replaced with fresh medium containing CB839 or AuR-CB839 NPs in DMEM with a final drug concentration of $1 \mu \mathrm{mol} / \mathrm{L}$ per well. After a $72 \mathrm{~h}$ incubation period at $37^{\circ} \mathrm{C}$, the NP-medium was removed and new culture medium was added every 3 days for 3 weeks. Finally, the plates were washed with PBS and the colonies were fixed using ice-cold methanol. Prior to counting the colonies, these were stained with a 0.5 vol.\% crystal violet solution in methanol, washed with water and air-dried. Due to the nature of intrinsic adherent growth of U87 cells, these plates were not coated with poly-D-lysine.

Agarose method [45]: Prior to embedding the cells into the soft-agar-medium dilution, the cells were incubated with CB839 or AuR-CB839 NPs in DMEM (1 $\mu \mathrm{mol} / \mathrm{L})$ for $72 \mathrm{~h}$. Sixwell flat-bottom plates were coated with $1.5 \mathrm{~mL}$ of neurosphere medium containing $1 \mathrm{vol} . \%$ of melted agarose at $70{ }^{\circ} \mathrm{C}$ for $1 \mathrm{~h}$. $2 \mathrm{~mL}$ of the treated cell suspension (1000 cells/well) with 0.6 vol. \% agarose were added and incubated for $1 \mathrm{~h}$ at room temperature before adding $2 \mathrm{~mL}$ medium on top. After this time, the medium on the top layer was replaced with $2 \mathrm{~mL}$ fresh medium every 3 days for 3 weeks. At last, the top layer was removed and the plates were incubated overnight at $37^{\circ} \mathrm{C}$ with $1 \mathrm{~mL}$ of a $1 \mathrm{~g} / \mathrm{L}$ 4-nitro blue tetrazolium chloride solution in PBS before counting the formed colonies.

All experiments with both methods were done in triplicates and the results were expressed as mean values accompanied by standard deviations.

\subsection{Fluorescent Microscopy}

After synthesis, AuPVA-FITC NPs were dialyzed, centrifuged and resuspended in $50 \mathrm{~mL}$ of DMEM (see Section 2.5). In Equation (4) (Section 3.2), we estimate the number of AuPVA NPs per batch to $5 \times 10^{17}$, thus giving a concentration of $5 \times 10^{17} \mathrm{NPs} / 50 \mathrm{~mL}$ or $10^{19} \mathrm{NPs} / \mathrm{L}$. From the Au-FITC-DMEM dispersion, $5 \mu \mathrm{L}$ were added to a $1 \mathrm{~mL}$-well containing 100,000 GBM cells. Subsequently, we estimate the concentration of AuPVA-FITC $\mathrm{NPs}$ to be $5 \times 10^{13} \mathrm{NPs} / \mathrm{mL}$ (or the ratio $5 \times 10^{8} \mathrm{NPs} /$ cell), based on the amount of gold precursor used for each synthesis batch and assuming a 100\% conversion (cf. Equation (4)). GBM cells were grown in spheroid culture $(70-150 \mu \mathrm{m})$ and incubated with AuPVA-FITC NPs for $1 \mathrm{~h}$. At the end of the incubation, the spheroids were washed three times with PBS and fixed with 70\% methanol for 15 minutes. Then the fixed spheres were processed for frozen sections. Briefly, the spheres were embedded into frozen tissue medium and frozen/stored at $-20{ }^{\circ} \mathrm{C}$ until they were processed for sectioning. The specimens were cut into 5-7 $\mu \mathrm{m}$ sections using a CM1900 Cryostat (Leica, Nussloch, Germany). For the staining process, the sections were rinsed 3-times with PBS and incubated with a DAPI solution $(0.1 \mu \mathrm{g} / \mathrm{mL}$ in PBS) for $2 \mathrm{~min}$. After rinsing the slides with PBS, the specimens were either directly mounted in slide mounting solution and covered with a coverslip or were further treated with Trypan Blue to quench extracellular fluorescence. A 0.1 vol.\% Trypan Blue solution was added to the section, followed by direct mounting and covering the sample. The slides were analyzed using a Zeiss Axiovision Apotome.2 confocal microscope (Zeiss, Oberkochen, Germany) and the software ZEN Blue (2.3, SP1, black, 64 bit, release version 14.0.0.0 also from Zeiss). 


\section{Results and Discussion}

\subsection{Synthesis and Characterization of $A u N P s$}

In order to bind CB839 to a nanocarrier, several polymeric capping ligands with different reactive groups were deposited on the surface of Au NPs as anchors. The synthesis of these gold "nanovehicles" consisted mainly of a reduction of an equal amount of gold(III) salt $\mathrm{KAuCl}_{4}$, using sodium citrate as a reducing agent. Starting from citrate coated gold (AuCit) NPs, made with a modification of the Turkevich method [46], spherical monodisperse particles were synthesized (vide infra), which were later used in a ligand exchange reaction to obtain polymer coated NPs, e.g., with poly(ethylene glycol) methyl ether thiol (AuThioPEG NPs) and with polyvinyl pyrrolidone (AuPVP NPs), respectively. Polyvinyl alcohol-coated gold (AuPVA) NPs were synthesized in a straight-forward one-pot reaction. The polymers ThioPEG, PVA, PVP, and PEI were chosen due to their known biocompatibility and their affinity for gold, as well as to provide a variety of different functional groups, which might successfully load CB839 onto the nanocarriers. Additionally, AuCit NPs were also included to see if Au presents any interaction with CB839 before any ligand exchange reaction with polymers.

TEM investigations of these samples show an overall spherical morphology of the $\mathrm{Au}$ NPs with almost no degree of agglomeration (Figure 2) and NP sizes between 8 and $15 \mathrm{~nm}$ (Figure S2, Supplementary Materials (SM)). While citrate NPs had a size of $15 \pm 2 \mathrm{~nm}$ (Figure 2a), a subsequent citrate-to-polymer exchange with ThioPEG resulted in NPs with an unchanged size of $15 \pm 2 \mathrm{~nm}$ (Figure 2b) and with PVP gave NPs with $11 \pm 2 \mathrm{~nm}$ average size (Figure 2c). By using the same amounts of gold precursor in the presence of PVA, spherical AuPVA NPs with a size of $8 \pm 2 \mathrm{~nm}$ (Figure 2d) and with PEI smaller-sized $4 \mathrm{~nm}$ AuPEI NPs [25] were synthesized and evaluated as potential drug delivery systems.



Figure 2. TEM images of AuCit (a), AuThioPEG (b), AuPVP (c), and AuPVA (d) NPs, captured at $50,000 \times(\mathbf{a}), 100,000 \times(\mathbf{b})$, and $150,000 \times(\mathbf{c}, \mathbf{d})$ magnification.

After reacting the various Au-Polymer NPs with CB839, no apparent size increase was observed for any of the NP types except for AuPEI (Figure S3, SM). There was however a slight reorganization between the Au cores, especially in the case of AuPVA and AuPVP NPs (Figure S3c,d, SM), most likely due to an alteration in surface chemistry and charge after interaction of the polymers with CB839.

\subsection{Quantification of CB839 Loading}

Subsequently, the amount of CB839 attached to the NPs was examined by collecting supernatants of all samples after centrifugation and quantifying the not adsorbed, remaining 
drug concentration via HPLC analysis. For this purpose, a method capable of efficiently separating CB839 in all NP samples was developed and optimized. By using a mixture of methanol and water as mobile phase, CB839 could be identified after a retention time of only $9 \mathrm{~min}$ and its concentration could be calculated with a standard calibration curve (Figure S4, SM). The drug loading efficiency (DLE) of AuCit, AuThioPEG, AuPVA, AuPVP and AuPEI NPs was calculated according to Equation (1) and results are displayed in Table 1.

$$
\begin{aligned}
\text { Drug Loading Efficiency }(\%)= & \frac{\text { Total amount of CB839 used-remaining CB839 amount in supernatant }}{\text { Total amount of CB839 used }} \times 100 \% \\
& =\frac{\text { Amount of loaded CB839 }}{\text { Total amount of CB839 used }} \times 100 \%
\end{aligned}
$$

Table 1. Drug loading efficiency of Au NPs ${ }^{\text {a }}$.

\begin{tabular}{cc}
\hline Au NPs & Drug Loading Efficiency (\%) \\
\hline AuCit & 8 \\
AuThioPEG & 4 \\
AuPVA & 12 \\
AuPVP & 0 \\
AuPEI & 1 \\
\hline
\end{tabular}

${ }^{a}$ From HPLC determination in supernatant solution according to Equation (1).

From all five ligands used to cover the gold NPs (Figure S1, SM), PVA seems to be the most effective in loading up to $12 \%$ CB839 on the surface of NPs. This finding can probably be explained by the strong interaction of the amide group in CB839 with the numerous hydroxyl groups in the PVA chains, which has been previously exploited to bind or stabilize hormones, proteins and other pharmaceuticals $[47,48]$. Here, the hypothesis is that the $\mathrm{OH}$ groups of PVA can act both as hydrogen bond acceptors from the amide-NH groups of CB839 and donors to the aromatic nitrogen atoms and to the amide $\mathrm{C}=\mathrm{O}$ groups of CB839, which leads to stronger supramolecular interactions with CB839, compared to the other polymers. Similarly, the different properties between NP types such as core size, polymeric shell and surface charge can affect the loading efficiency of each Au NP. The small size and positive charge of AuPEI NPs [25] seem to be counterproductive to load CB839. Larger $15 \mathrm{~nm}$ AuCit NPs show the second highest DLE after AuPVA NPs, due to possible electrostatic interactions with CB839. Aside from NP size and surface charge, the chemical nature of the polymer shell used for Au NPs can also play an important role on the DLE. Citrate and PVA feature strong hydrogen bond donor and acceptor $\mathrm{OH}$ groups. The $\mathrm{NH}$ and $\mathrm{NH}_{2}$ groups in PEI are already weaker $\mathrm{H}$ bond donors and acceptors, with the latter getting lost upon protonation. Also, upon protonation, the $\mathrm{H}$ bond donor function of the $\mathrm{NH}_{2}{ }^{+}$and $\mathrm{NH}_{3}{ }^{+}$groups will then be engaged by the counter anion. PVP is no $\mathrm{H}$ donor but only a week acceptor, while ThioPEG has no $\mathrm{H}$ bonding capabilities. Even though in theory a stronger CB839 binding capability was expected from PVP due its hydrogen bond accepting $\mathrm{C}=\mathrm{O}$ groups, AuThioPEG showed a higher DLE (Table 1). A reason for this counterintuitive behavior might have to do with the polymer chain arrangement around the Au NPs. ThioPEG with $M_{w} \sim 800 \mathrm{~g} / \mathrm{mol}$ has shorter chain lengths than polyvinyl pyrrolidone (PVP) with $M_{w} \sim 3500 \mathrm{~g} / \mathrm{mol}$. Shorter polymer chains cannot form a dense polymer layer as longer ones can. Thus, shorter polymer chains will be more amenable to embed guest molecules.

Even though DLE results give an overall impression of the loading success among samples, they are dependent of the concentration of CB839 used and thus only describe the efficiency of each specific reaction. For better interpretation of the experiments and the later application of the CB839-NPs, calculating the amount of CB839 molecules that are loaded per NP might be more relevant. This was done taking AuPVA-CB839 NPs as an example. 
Based on the spherical shape and the radius of Au NPs (e.g., $r=4 \mathrm{~nm}$ ) determined by TEM measurements, the volume of a single NP can be calculated by Equation (2):

$$
V_{N P}=\frac{4}{3} \times \pi \times r^{3}=268 \mathrm{~nm}^{3}
$$

and its mass with Equation (3) (density of $\mathrm{Au}, \rho_{\mathrm{Au}}=19.32 \mathrm{~g} / \mathrm{cm}^{3}$ ):

$$
m_{N P}=\rho \times V=5.18 \times 10^{-18} \mathrm{~g} .
$$

Since $5 \mathrm{mg} \mathrm{KAuCl}_{4}$ were used in the reaction, the mass of Au in the salt $\left(m_{A u}=2.6 \mathrm{mg}\right)$, assuming a $100 \%$ conversion from $\mathrm{KAuCl}_{4}$ to $\mathrm{Au} \mathrm{NPs}$, can be used to determine the total number of Au NPs $\left(N_{N P s}\right)$ in the sample:

$$
N_{N P s}=\frac{m_{A u}}{m_{N P}}=5 \times 10^{17} .
$$

From the molar amount of CB839 applied in the synthesis of AuPVA-CB839 NPs, the number of CB839 molecules can be calculated as:

$$
N_{C B 839}=n_{C B 839} \times N_{A}=2.6 \times 10^{18}
$$

$n_{C B 839}=4.4 \times 10^{-6} \mathrm{~mol}, N_{A}=6.022 \times 10^{23} \mathrm{~mol}^{-1}$ (Avogadro constant).

Since the AuPVA NPs loaded 12\% of the added CB839, according to the DLE results, the number of CB839 molecules loaded onto the NPs $\left(N_{C B 839 l o a d e d}\right)$ is:

$$
N_{C \text { B839loaded }}=N_{C B 839} \times 0.12=3.2 \times 10^{17} \text { molecules } .
$$

Finally, the number CB839 molecules loaded per NP (“Loading yield”) can be calculated using Equation (7):

$$
\text { Loading yield }=\frac{N_{C B 839 l o a d e d}}{N_{N P}}=0.6 .
$$

Thus, we conclude that approximately $60 \%$ of AuPVA NPs carry one drug molecule. Since this estimation was made based on the ideal 100\% NP formation from the gold precursor, this value represents the lowest possible loading of CB839 onto AuPVA NPs and might be higher in reality.

To further evaluate this result, the size of the CB839 molecule was compared to the size of a NP. With help of a crystal structure published by Huang et al. [49], we estimated the length of the CB839 molecule in its folded conformations to be approximately $2 \times 0.8 \mathrm{~nm}$, and in its linear form $2.9 \times 0.75 \mathrm{~nm}$, taking the van der Waals radii into account (Figure 3 and Figure S5, SM). Therefore, since the size of CB839 is in the same order of magnitude as the size of a NP, it would be difficult to achieve a much higher CB839 loading with NPs of this small size. Even though we believe $60 \%$ to be a good result, improvement of the loaded amount might be possible by adjusting reaction parameters or using larger NP sizes. While these DLE values are the result of experiments using a single CB839 molar amount of $n_{C B 839}=4.4 \times 10^{-6} \mathrm{~mol}$, we will continue trying to improve the DLE of AuPVA NPs in the future by testing additional CB839 concentrations in the reaction. 


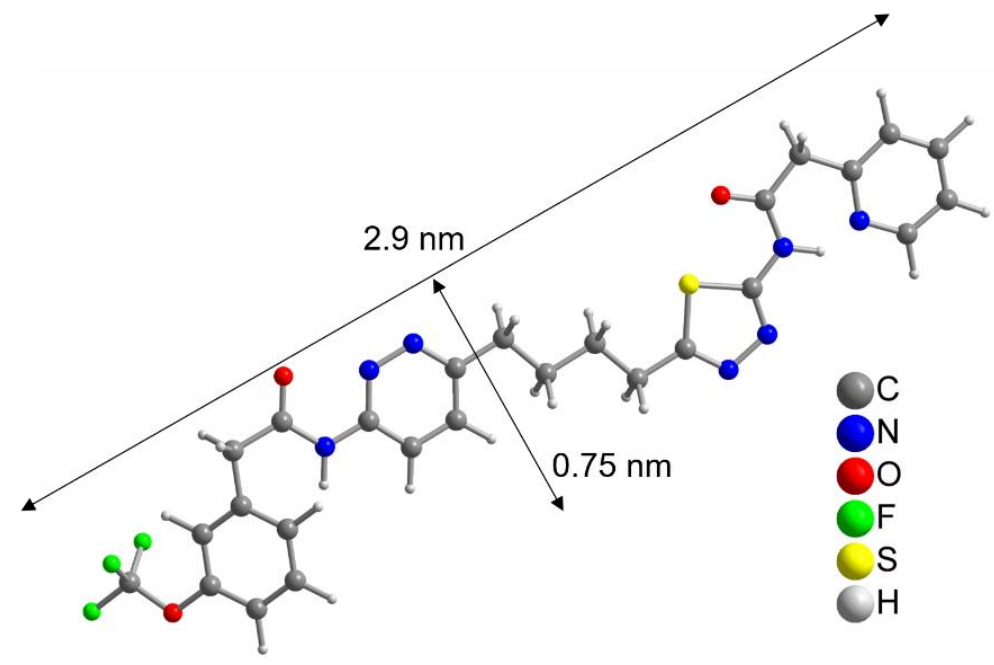

Figure 3. Linearized structure of the CB839 molecule. For the folded conformations in the glutaminase C complex, see Figure S5, SM.

\subsection{Physicochemical Characterization of AuPVA-CB839 NPs}

Prior to its application in cells, the physicochemical properties AuPVA-CB838 NPs, the NP type with highest CB839 loading, were investigated in-depth. Besides quantifying the amount of CB839 bound to the NPs, the immobilization of the drug on the surface of the AuPVA NPs was confirmed through various spectroscopic methods. IR spectroscopy of the dried NP-drug conjugate showed characteristic C-F stretching $\left(1142 \mathrm{~cm}^{-1}\right)$ and bending (735 $\mathrm{cm}^{-1}$ ) vibrations of the $\mathrm{CF}_{3}$ group of $\mathrm{CB} 839$, as well as the $\mathrm{N}-\mathrm{H}$ band of its amide group $\left(1534 \mathrm{~cm}^{-1}\right)$ and the aromatic $\mathrm{C}-\mathrm{H}$ bending $\left(703 \mathrm{~cm}^{-1}\right)$ vibration (Figure S6, SM).

Moreover, UV-VIS spectroscopy of the AuPVA-CB839 NPs showed an additional absorbance maximum at $240 \mathrm{~nm}$ corresponding to CB839 compared to the AuPVA NPs, which only showed the characteristic plasmonic band at $550 \mathrm{~nm}$ (Figure 4). These spectra also show no visible size increase or agglomeration of the AuPVA NPs after reaction with CB839, since the $550 \mathrm{~nm}$ absorbance signal of AuPVA-CB839 NPs did not shift to larger wavelengths.

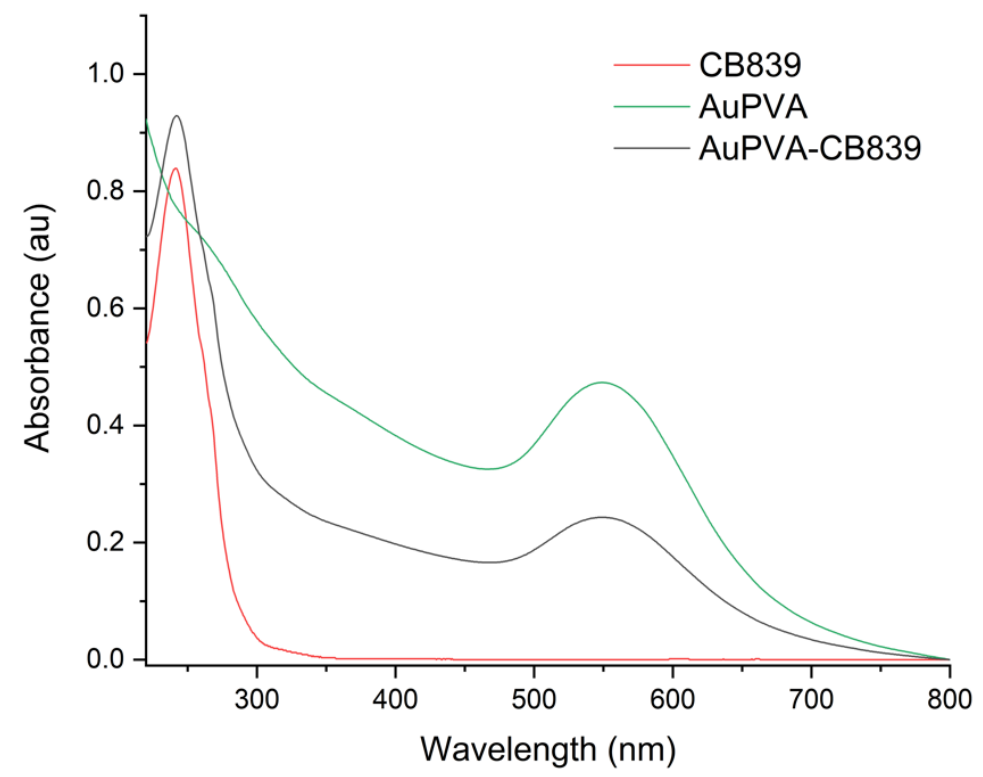

Figure 4. UV-VIS spectra of CB839 (red), AuPVA (green), and AuPVA-CB839 NPs (black). 
Using energy-dispersive X-ray spectroscopy (EDX), elemental maps of AuPVA-CB839 NPs were collected on a scanning transmission electron microscope (STEM). The elements gold, corresponding to the AuPVA NPs and fluorine from CB839 are displayed in maps in Figure 5. Here, fluorine appears to be in the same area as gold and to form similar circular patterns correlated with the Au map. Since electrons scatter strongly from $\mathrm{Au}$, the contrast in the fluorine (F-K) X-ray map is likely caused by an increase in the Bremsstrahlung background. In order to confirm the presence of F in the vicinity of Au NPs and to observe the influence of background radiation, X-ray spectra taken on Au NPs were compared against such taken from surrounding areas (Figure S7, SM).
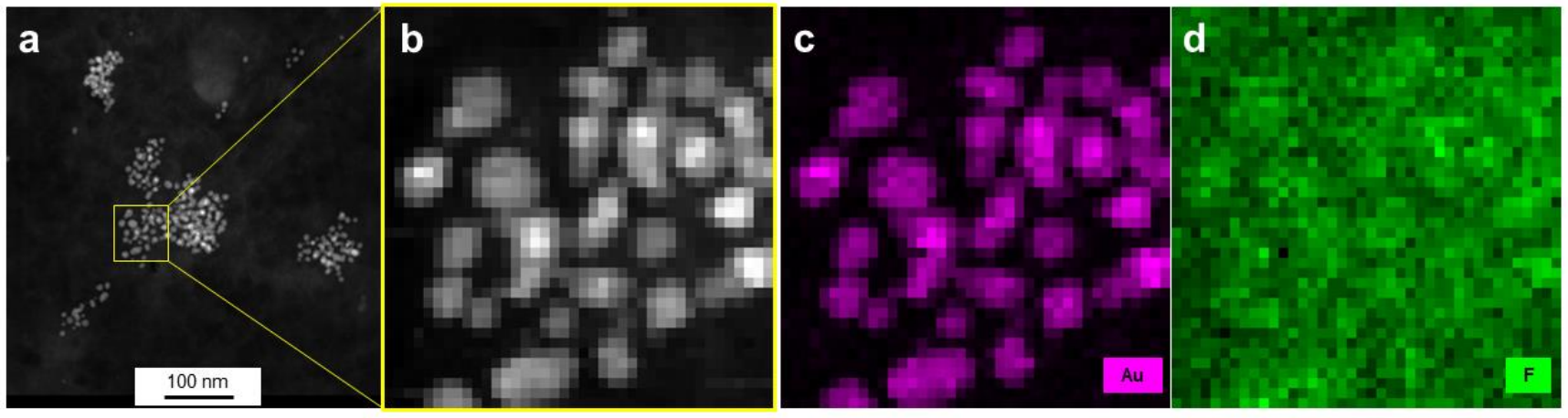

Figure 5. HAADF-STEM images (a,b) and EDX elemental mapping (c,d) of AuPVA-CB839 NPs. Gold, corresponding to the NPs is shown in pink and fluorine contained in CB839 in green.

From the Au-M $\alpha_{1}$ elemental map (Figure S7a, SM), the inner areas and the edges of NPs were carefully selected (Figure S7b, SM) and three EDX spectra from these scan point subsets were created by averaging all points of a subset (Figure S7c, SM). Since the Au-M $\alpha_{1}$ signal at $2123 \mathrm{eV}$ (red dot, Figure S7c, SM) is strongest on the particles, weaker at edges and absent next to the particles, we believe the threshold values for the assignment to edge and particle interior were chosen correctly. There is no denying that stronger Bremsstrahlung occurs when the electron beam passes through the strongly scattering Au particles, as can be seen in the pure background regions of the spectra, e.g., at 1200-1500 eV. However, all spectra show a slight elevation of the EDX signal at $677 \mathrm{eV}$ (F-K peak, black dot, Figure S7c, SM), independent of location. As AuPVA NPs are surrounded by a large-sized surface polymer able to bind CB839 molecules, a F-K emission around the NPs (black scan area on Figure S7b, SM) can also be expected. Thus, we conclude that even though the discovery of a low amount of F atoms on Au NPs present upon loading CB839 is difficult due to the detection limits of the equipment, CB839 is found near the Au NPs.

Thermogravimetric analysis (TGA, Figure S8, SM) showed that the AuPVA-CB839 conjugates are stable to about $200{ }^{\circ} \mathrm{C}$.

The colloidal properties of AuPVA-CB839 NPs were also investigated using DLS measurements (Figure S9, SM). In water, the hydrodynamic diameter of AuPVA-CB839 NPs was approximately $20 \mathrm{~nm}$, while in culture media (DMEM) their size increased to $80 \mathrm{~nm}$. This larger NP size in DMEM is to be expected, due to the formation of a protein corona around the surface of NPs as they interact with several proteins contained in cell culture media [50].

\subsection{In Vitro Effect of AuPVA-CB839 NPs in GSCs}

Following these investigations, the first in vitro tests in classical cell models of adherently grown U87 cells were conducted with AuPVA, AuCit, and AuThioPEG NPs (Figure S10, SM). We followed in our analysis the previously recommended use of quantifying cell colony formation efficiency (CFE) to functionally assess the cytotoxicity of nanomaterials [41]. 
Because the ability of Au NPs to absorb visible light can lead to false positive results when using a photometer to determine cell viability (Figure S11, SM), a quantification with the CFE method is most suitable for our study. This assay avoids any interference of metals, in our case $\mathrm{Au}$, with other test components or optical detection methods thus minimizing signal disturbance and false recordings. The biological assessment was performed in a robust in vitro platform of $n=4$ different glioma models featuring $n=3$ glioma stem cell systems. For each model, we quantified the ability to form monolayer and spheroidic colonies in the presence of different treatment conditions.

Given that JHH520, GBM1, and BTSC407 GSCs are not adherent, the CFE assay was modified using poly-D-lysine, a polycationic amino acid polymer, which is able to interact with anionic parts of neural cells, thus effectively attaching them to a surface. As Figure S12, SM shows, this attachment endured the NP and staining treatments of GBM cells and allowed for data interpretation by counting the colonies formed due to the ability of GSCs of making colonies from single cells [22]. The less colony formation, the more effective the drug treatment. Our tests reveal that treating the cells with AuPVA-CB839 NPs containing $1 \mu \mathrm{mol} / \mathrm{L}$ CB839 impaired tumor cell growth, as benchmarked to treatment with $1 \mu \mathrm{mol} / \mathrm{L}$ CB839 only (Figure 6). The differences in the amount of reduction on CFE between the 2D (poly-D-lysine) vs. 3D (agarose) assay could be explained by the different susceptibly of the cells when grown in different conditions, whereby 3D more closely recapitulated the actual tumor physiology [32]. In addition, the variations in experimental handling sequence could result in different error introduction into the assays (pretreatment of cells for setting the Agarose assay, washing steps in 2D poly-D-lysine assay). Importantly however, the general trend of augmented therapeutic potential of our nano-delivered CB839 as compared to the unmodified substance is shown in all tested cell models with both assays, thereby supporting our technology for the development of an anti-metabolic therapy potentially able to eradicate tumors with stem cell properties.

The percentage of colony formation in U87 cells with CB839 alone and with AuPVACB839 NPs differed only slightly when comparing both incubation methods (Figure 6a). JHH520 cells (Figure 6b) presented a similar reaction than GBM1 cells (Figure 6c), as they are both glutaminase-high expressing lines [22]. Interestingly, the in vitro clonogenicity of BTSC407 cells (Figure 6d) after treatment with AuPVA-CB839 NPs in agarose was only about $1 \%$, compared to $30 \%$ with a CB839 treatment without NPs (relative to the control set at 100\%), which speaks for the NP potential to enhance the drug effect, even in cell lines thought to be resistant due to lower GLS1 activation levels [22]. Based on our previously conducted functional assays with CB839 and other pharmacological GLS inhibitor C968, using the same cell models as in this study, we believe that the total GLS1 protein abundancy predicts for the sensitivity of GBM cells to anti-GLS1 directed drugs. The fact that U87 and BTSC407 cells have comparably low GLS1 expression as opposed to GBM1 and JHH520 not only shows that our applied disease modeling technology can recapitulate the variation of target activity found in patients [21,22], but also reflects the molecular heterogeneous nature of this disease. Thus, this inter- and intratumoral cell metabolic heterogeneity may limit the durable effects of such monotherapies and the differences in saturation of GLS1 blockage could be a reason for the observed differences. Moreover, compared to serum-free spheroid models, the serum-containing in vitro growth conditions of the U87 cell line, known to dampen the effects of pharmaco interventions [51], can also be a reason for higher GLSi resistance. Acknowledging that this is rather a technical limitation than a translational relevant reason for possible source of therapy resistance, we added three spheroid, serum-free models (JHH520, BTSC407, and GBM1), in our project.

To our best knowledge, this is the first report of functionalizing the most promising GLSi compound CB839 to inorganic nanocarriers and performing bio validation. Our technology accompanies a previous report on BPTES-loaded poly(lactic)-glycolic acid NPs [52] and confirms the observation that application of nanotechnology is a powerful strategy to improve the therapeutic capacity of this drug class. 

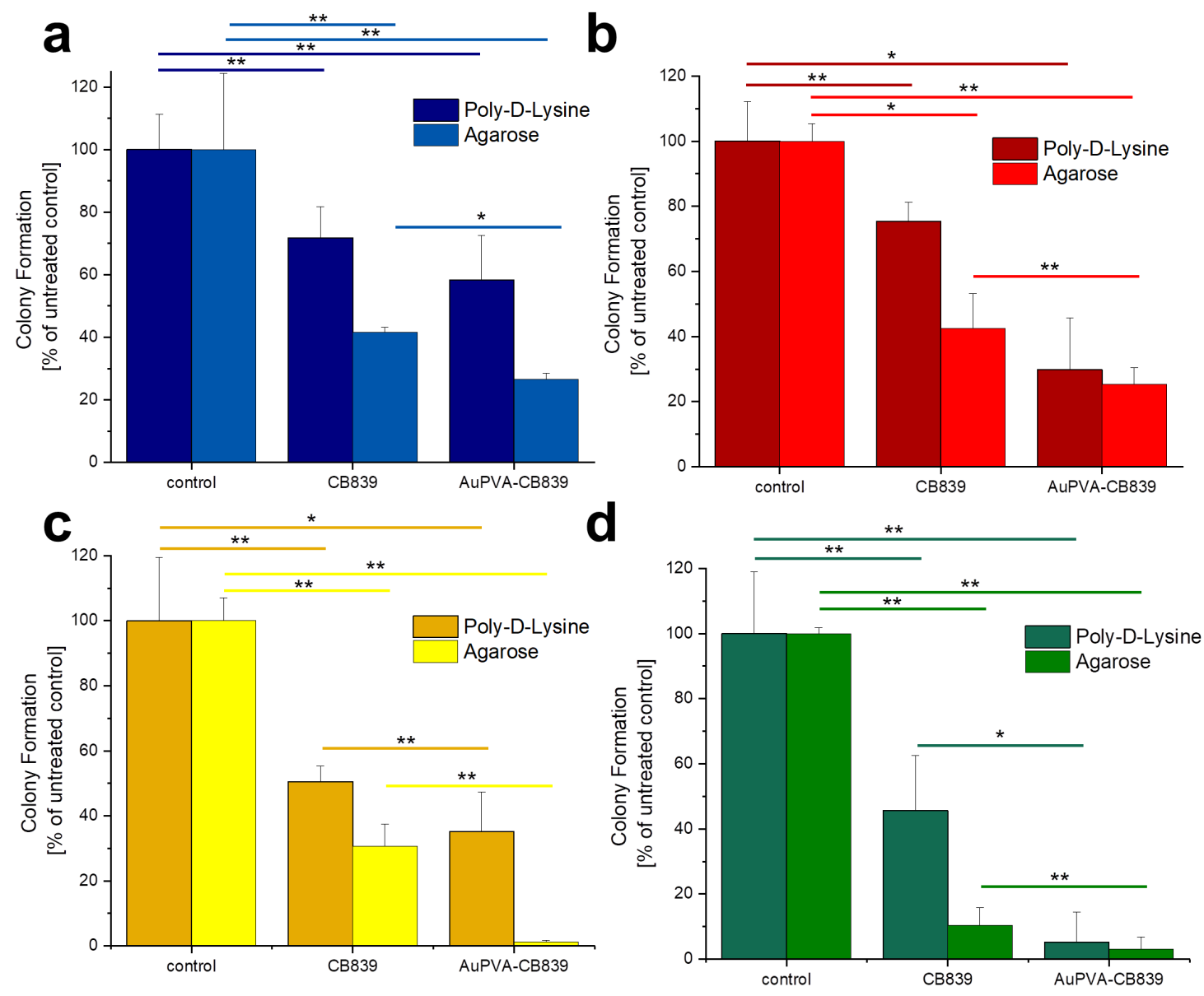

Figure 6. Colony Formation of U87 (a), JHH520 (b), GBM1 (c), and BTSC407 (d) cells after incubation with AuPVA-CB839 NPs, using both the 2D poly-D-lysine and the 3D agarose method. Dark columns in (a) are labelled as poly-D-lysine for comparison, even though no adhesion polymer was used since cell model U87 grows adherent already. A two-sample t-test was performed using Origin 8 software and significances are indicated: ${ }^{*} p>0.05,{ }^{* *} p>0.03$.

While the effect of CB839-loaded Au NPs on colony formation is shown, tests regarding quantification of the amount of inhibitor delivered into cells for each case are underway. Similarly, enzyme activity inhibition studies like those made in GSCs for CB839 [22] are pending for Au-CB839 NPs to gain additional knowledge about how they affect the target, as well as their intracellular delivery and release. Even though we recently benchmarked the phenotypic effects of CB839 against the absence of effects when applying DMSO in the same cell models as in the current study [22], we acknowledge that the repetition of these control experiments using ethanol solvent would be beneficial to further support some conclusions of this work. In the future, we will also include our CB839-loaded Au NPs in further screening assays in order to characterize their effect and toxicity more comprehensively in a high-throughput manner [53].

While the blood-brain barrier permeability of CB839 is challenging, as described in several in vitro studies $[19,54]$, its specificity to inhibit GLS1 and the connection between response and IDH1 DNA mutation status of cancer patients [9] makes it a promising candidate for precision cancer therapy. Although an increased diffusion through the barrier is expected when attaching the small molecule to Au NPs [55-57], CB839 could also be part of an intraventrical, intrathecal, or localized intracranial chemotherapy. For intracranial chemotherapy, the BBB problematic could even be avoided because the drug is directly applied to the tumor cavity during tumor resection [58,59]. As has been well described in the literature for the study of GBM in vivo [60-63], we suggest a xenograft approach of human tumor stem cell models in rodent carriers, ideally in immune-tolerant models [64], 
to investigate the immune relevance of the applied intervention using nanocarried-CB839 in the future. Such an immunocompetent mouse model for human GBM cells-which has also been recently used for testing additional disease types [65] —would also help to study the effects of Au-CB839 NPs on the immune microenvironment of the tumor. Given the emergence of immune therapies as effective cancer treatments, the inclusion of such assays in future drug development projects are desirable to increase translational relevance.

\subsection{Cell Internalization}

To visualize the GSCs penetration potential by the Au-Polymer CB839 conjugate, fluorescent labelling of our NPs and our tumor models was used to investigate the NP internalization in GBM cells (Figure 7). For this purpose, AuPVA NPs were functionalized with FITC, resulting in AuPVA-FITC NPs. These fluorescent AuPVA NPs are used as a proof-of-concept to demonstrate that the PVA coated Au NPs are able to penetrate GSCs. We have only fluorescent-stained the AuPVA NPs with FITC because these NPs had the highest DLE. From our previous work [25], we realized the importance of the surface ligand on the degree of NP internalization and had discovered differences when testing the same NPs in different GBM cell lines. Thus, we wanted to make sure that AuPVA NPs were able to penetrate GSCs if they are later to be loaded with CB839.



Figure 7. Exemplary fluorescence microscopy images of JHH520 cells after incubation with AuPVA-FITC NPs. Image (a) shows DAPI signals of cell DNA, image (b) FITC signals corresponding to AuPVA-FITC NPs and (c) a combined DAPI and FITC image.

The successful attachment of FITC to the Au NPs relies on the presence of a sulfur atom in the isothiocyanate group of the fluorophore. Given the strong affinity of gold for sulfur, FITC is able to coordinatively bind to Au NPs though relatively stable bonds [66,67]. Free FITC with its isothiocyanato, -NCS group is able to form Au-S bonds on the gold metal surface, requiring only minimal reaction time $[68,69]$. This attachment was confirmed by fluorescence spectroscopy (Figure S13, SM), which showed a quenched but still present fluorescence signal of AuPVA-FITC compared to FITC due to the interaction of the fluorophore with $\mathrm{Au}$ [70]. Moreover, the stretching band of the $\mathrm{C}=\mathrm{O}$ group of the lactone in FITC was visible at $1728 \mathrm{~cm}^{-1}$ in IR spectra taken from AuPVA-FITC NPs (Figure S14, SM), as well as stretching vibrations from the benzene ring at 1601 and $1435 \mathrm{~cm}^{-1}$. The FITC loading efficiency of AuPVA-FITC NPs (see Equation (S1) in the SM) was calculated using UV-VIS spectroscopy (Figure S15, SM). By comparing the absorbance intensity of the supernatant recovered after NP centrifugation (unloaded FITC) and the absorbance of total FITC used for the reaction, the loading was estimated to be approximately $23 \%$. According to zeta potential measurements, AuPVA-FITC NPs remain stable in water for at least one hour at room temperature (Figure $\mathrm{S} 16, \mathrm{SM})$. After this time, the surface charge of the NPs $(-16 \mathrm{mV}$ at $0 \mathrm{~min})$ continues to decrease until reaching a zeta value of $-27 \mathrm{mV}$, similar to the value of AuPVA NPs without FITC. Therefore, only freshly-prepared AuPVA-FITC NPs were used for further experiments in order to guarantee that a sufficient amount of FITC was still present on the NPs.

AuPVA-FITC NPs were added to the cells and sphere sections were studied under a fluorescence microscope. After staining cell DNA (Figure 7a), a green FITC signal 
(Figure $7 \mathrm{~b}$ ) corresponding to the NPs were visible in the same area (Figure 7c). Thus, we conclude that PVA is a suitable capping ligand for Au NPs, as it also allows their internalization, which is visualized after quenching extracellular fluorescence using Trypan Blue (Figure S17, SM).

Even though it has been demonstrated that Au NPs can be internalized through various endocytosis-based pathways or by direct cytoplasmic uptake [71], additional experiments are needed to determine the internalization mechanism of Au-CB839 NPs.

\section{Conclusions}

The synthesis of five Au NP types (four with polymer ligands and one with citrate) resulted in particles of 8-15 nm in size with different polymeric capping ligands. Despite the lack of functional groups with high chemical reactivity and a significant steric hindrance from its large size, the CB839 molecule could be immobilized on the surface of Au NPs through physical adsorption and electrostatic interactions with the polymers. AuPVA NPs were able to immobilize the highest amount of CB839, displaying a DLE of $12 \%$. Calculations estimated that at least $60 \%$ of all AuPVA NPs carry one CB839 molecule. Even though characterization and quantification of CB838 loading using chromatographic and spectroscopic methods is challenging, AuPVA-CB839 NPs demonstrated improved biological results. In vitro experiments in GSCs showed an enhanced effect of CB839 when delivered by $\mathrm{Au}$ NPs as compared to the neat drug solution. As expected due to the cellular and molecular heterogeneity of GBM, the therapy effect varied depending on the cell lines used. Our study presents and compares two suitable bioassays to test the effect of CB839-loaded Au nanocarriers. While 3D cell cultures are better models to mimic in vivo conditions, $2 \mathrm{D}$ cultures greatly facilitate a treatment with nanomaterials. Although human cell assays emerge as the preferred option to assess therapy efficacy and toxicology risk, current Au-drug development projects require testing in humanized animal models to enhance clinical prediction. Given the previously unmet need of treating GBM with effective, long-lasting therapies, our work raises hope to improve future care of patients using anti-cell metabolism directed approaches. Moreover, exploiting the unique optical and magnetic properties of Au NPs as theranostic devices are underway, thereby further extending the list of options how inorganic chemistry has the potential to improve neurooncology care, including clinical applied strategies such as photo- or hyperthermal therapy.

Supplementary Materials: The following are available online at https: / www.mdpi.com/1999-4 923/13/2/295/s1, Figure S1: Structural formula of citric acid $\left(\mathrm{H}_{3} \mathrm{Cit}\right)$ and of the repeat units of the polymers poly(ethylene glycol) methyl ether thiol (ThioPEG), polyvinyl alcohol (PVA), polyvinyl pyrrolidone (PVP) and branched polyethylene imine (PEI), Figure S2: Histograms of Au-citrate (AuCit) (a), AuThioPEG (b), AuPVA (c) and AuPVP (d) nanoparticles (NPs). ThioPEG = poly(ethylene glycol) methyl ether thiol, PVA = polyvinyl alcohol, PVP = polyvinyl pyrrolidone., Figure S3: TEM images and histograms of AuCit-CB839 (a,f), AuThioPEG-CB839 (b,g), AuPVA-CB839 (c,h), AuPVPCB839 (d,i) and AuPEI-CB839 (e,j) NPs. Images were captured at 200,000× (a), 100,000× (b) and $150,000 \times(c, d, e)$ magnification, Figure S4: HPLC chromatogram (a) and standard calibration curve (b) used for CB839 quantification., Figure S5: Structures of the two CB839 molecules, extracted from "glutaminase C in complex with inhibitor CB-839" (PBD ID: 5HL1, MMDB ID: 142270) [1]. Hydrogen atoms were added with Mercury [2], Figure S6: IR spectra of AuPVA-CB839 NPs (in black), CB839 (in red) and AuPVA NPs (in green), Figure S7: STEM EDX analysis of AuPVA-CB839 NPs. Elemental maps from the Au-M $\alpha_{1}$ intensity at $2123 \pm 60 \mathrm{eV}$ (a), NP inner and edge area selection ((b), all scan points assigned to edges are red, all those assigned to NP interiors are yellow and all other points are black) and corresponding EDX spectra of the three areas (c). Note: In (a) image pixels represent points where the electron probe was placed. A scan of $40 \times 40$ pixels was performed so, Figure S7a is shown at raw data resolution, Figure S7b is a mask applied to spectroscopic images at the resolution of the measurement, Figure S8: TGA curve for the decomposition of AuPVA-CB839 NPs (in black), CB839 (in red) and PVA (in blue), Figure S9: DLS measurements of AuPVA-CB839 NPs in water(a) and in DMEM (b), Figure S10: Colony Formation after treatment of U87 cells with CB839, AuThioPEGCB839, AuCit-CB839 and AuPVA-CB839 NPs. Untreated cells were used as control, Figure S11: 


\begin{abstract}
Absorbance measurements after incubation of GBM1 cells with culture medium (Control), AuPVA and AuPVA-CB839 NPs. These values were measured after performing the MTT Assay, as described previously [3]. Even though the MTT absorbance should be highest at the control (highest possible cell viability under the chosen conditions), wells treated with Au NPs show superior absorbance values even after several washing steps to remove NPs. This observation stresses the importance of choosing label-free non-optical methods to assess the toxicity of compounds accompanied by metal NPs, Figure S12: BTSC407 colonies after incubation with CB839 (wells 1-3) and with AuPVA-CB839 NPs (wells 4-6) using poly-D-lysine, Figure S13: Fluorescence spectra of AuPVA-FITC NPs (red line) and FITC (green line), Figure S14: IR spectra of AuPVA-FITC NPs (in brown), FITC (in purple) and AuPVA NPs (in green), Figure S15: UV-VIS spectra used to determine the loading efficiency of FITC for AuPVA-FITC NPs. The purple (upper) line (FITC) indicates the absorbance of total FITC added to the reaction. The brown (lower) line (sup. AuPVA-FITC) corresponds to the absorbance of FITC, which was not loaded onto AuPVA NPs and was obtained from the supernatant after centrifugation of the AuPVA-FITC product, Figure S16: Zeta potential measurements of AuPVA-FITC NPs. (a): Comparison of zeta potential of AuPVA NPs (in red) and freshly-prepared AuPVA-FITC NPs (in green). (b): Time-dependent zeta potential values of AuPVA-FITC NPs in water at room temperature, Figure S17: Microscopic images of JHH520 cells with AuPVA-FITC NPs after Trypan Blue quenching of extracellular fluorescence. (a) shows DAPI staining of cell nuclei, (b) shows the fluorescent AuPVA-FITC NPs inside the cells and (c) is a combination of $(a, b)$.
\end{abstract}

Author Contributions: Conceptualization, B.G., U.D.K., and C.J.; methodology, B.G., A.-C.N.; software, B.G., A.-C.N.; validation, B.G.; formal analysis, B.G., A.-C.N., and J.B.; investigation, B.G. and A.-C.N.; resources, C.J. and U.D.K.; data curation, B.G.; writing-original draft preparation, B.G.; writing-review and editing, B.G., J.B., U.D.K., and C.J.; visualization, B.G.; supervision, U.D.K. and C.J.; project administration, U.D.K. and C.J.; funding acquisition, U.D.K. and C.J. All authors have read and agreed to the published version of the manuscript.

Funding: The work of Ulf Dietrich Kahlert is supported by the Federal Ministry of Education and Research (BMBF KZ 03VP03791), the Volkswagen Stiftung, the Hempel Family Foundation, the Brigitte- and Dr. Konstanze Wegener Foundation and the Sino-German Center for Science Promotion.

Institutional Review Board Statement: Ethical approval for the use of the cell models to study brain cancer biology was from the ethical commission of the medical faculty of Heinrich-Heine University (study ID 5841R, initial approval 31 March 2017, revised and renewed 16 September 2019).

Informed Consent Statement: Not applicable.

Data Availability Statement: The data presented in this study is contained within this article and its supplementary materials.

Acknowledgments: The authors thank the Ernst Ruska-Center, Forschungszentrum Jülich GmbH, Germany for access to the TEM facility under project number ER-C A-060. We acknowledge Constanze Uhlmann, Alexa Schmitz and Agustín Penagos for their support with this project. This article/publication is based upon work from COST Action CA 17140 "Cancer Nanomedicine from the Bench to the Bedside" supported by COST (European Cooperation in Science and Technology). Ulf Dietrich Kahlert thanks Hans-Jakob Steiger and Daniel Hänggi for their continuous support.

Conflicts of Interest: The authors declare no conflict of interest.

\title{
References
}

1. Yang, Y.; Hsieh, I.-Y.; Huang, X.; Li, J.; Zhao, W. Glioblastoma Stem-Like Cells: Characteristics, Microenvironment and Therapy. Front. Pharmacol. 2016, 7, 477.

2. Kahlert, U.D.; Mooney, S.M.; Natsumeda, M.; Steiger, H.-J.; Maciaczyk, J. Targeting cancer stem-like cells in glioblastoma and colorectal cancer through metabolic pathways. Int. J. Cancer 2017, 140, 10-22. [CrossRef]

3. Harder, B.G.; Blomquist, M.R.; Wang, J.; Kim, A.J.; Woodworth, G.F.; Winkles, J.A.; Loftus, J.C.; Tran, N.L. Developments in Blood-Brain Barrier Penetrance and Drug Repurposing for Improved Treatment of Glioblastoma. Front. Oncol. $2018,8,462$. [CrossRef]

4. Garnier, D.; Renoult, O.; Alves-Guerra, M.-C.; Paris, F.; Pecqueur, C. Glioblastoma Stem-Like Cells, Metabolic Strategy to Kill a Challenging Target. Front. Oncol. 2019, 9, 118. [CrossRef]

5. Cheng, L.; Wu, Q.; Guryanova, O.; Huang, Z.; Huang, Q.; Rich, J.N.; Bao, S. Elevated invasive potential of glioblastoma stem cells. Biochem. Biophys. Res. Commun. 2011, 406, 643-648. [CrossRef] 
6. Singh, S.K.; Clarke, I.D.; Terasaki, M.; Bonn, V.E.; Hawkins, C.; Squire, J.; Dirks, P.B. Identification of a cancer stem cell in human brain tumors. Cancer Res. 2003, 63, 5821-5828.

7. Singleton, D.C.; Dechaume, A.-L.; Murray, P.M.; Katt, W.P.; Baguley, B.C.; Leung, E.Y. Pyruvate anaplerosis is a mechanism of resistance to pharmacological glutaminase inhibition in triple-receptor negative breast cancer. BMC Cancer 2020, $20,470$. [CrossRef] [PubMed]

8. Zhang, J.; Mao, S.; Guo, Y.; Wu, Y.; Yao, X.; Huang, Y. Inhibition of GLS suppresses proliferation and promotes apoptosis in prostate cancer. Biosci. Rep. 2019, 39. [CrossRef] [PubMed]

9. Seltzer, M.J.; Bennett, B.D.; Joshi, A.D.; Gao, P.; Thomas, A.G.; Ferraris, D.V.; Tsukamoto, T.; Rojas, C.J.; Slusher, B.S.; Rabinowitz, J.D.; et al. Inhibition of glutaminase preferentially slows growth of glioma cells with mutant IDH1. Cancer Res. 2010, 70, 8981-8987. [CrossRef]

10. Choudhury, M.; Yin, X.; Schaefbauer, K.J.; Kang, J.-H.; Roy, B.; Kottom, T.J.; Limper, A.H.; Leof, E. SIRT7-mediated modulation of glutaminase 1 regulates TGF- $\beta$-induced pulmonary fibrosis. FASEB J. 2020, 34, 8920-8940. [CrossRef]

11. Hoerner, C.R.; Chen, V.J.; Fan, A.C. The 'Achilles Heel' of Metabolism in Renal Cell Carcinoma: Glutaminase Inhibition as a Rational Treatment Strategy. Kidney Cancer 2019, 3, 5-29. [CrossRef]

12. Yu, Y.; Yu, X.; Fan, C.; Wang, H.; Wang, R.; Feng, C.; Guan, H. Targeting glutaminase-mediated glutamine dependence in papillary thyroid cancer. J. Mol. Med. 2018, 96, 777-790. [CrossRef] [PubMed]

13. Zacharias, N.M.; Baran, N.; Shanmugavelandy, S.S.; Lee, J.; Lujan, J.V.; Dutta, P.; Millward, S.W.; Cai, T.; Wood, C.G.; PiwnicaWorms, D.; et al. Assessing metabolic intervention with a glutaminase inhibitor in real-time by hyperpolarized magnetic resonance in acute myeloid leukemia. Mol. Cancer 2019, 18, 1937-1946. [CrossRef] [PubMed]

14. Reckzeh, E.S.; Karageorgis, G.; Schwalfenberg, M.; Ceballos, J.; Nowacki, J.; Stroet, M.C.M.; Binici, A.; Knauer, L.; Brand, S.; Choidas, A.; et al. Inhibition of Glucose Transporters and Glutaminase Synergistically Impairs Tumor Cell Growth. Cell Chem. Biol. 2019, 26, 1214-1228. [CrossRef]

15. De Lartigue, J. Hallmark tumor metabolism becomes a validated therapeutic target. J. Community Support. Oncol. 2018, 16, e47-e52. [CrossRef]

16. Lukey, M.L.; Cerione, R.A. Starving the Devourer: Cutting Cancer Off from Its Favorite Foods. Cell Chem. Biol. 2019, 26, 1197-1199.

17. Study of CB-839 in Combination w/Paclitaxel in Patients of African Ancestry and Non-African Ancestry With Advanced TNBC (Clinical Trial ID: NCT03057600). Available online: https:/ / linicaltrials.gov/ct2/show/NCT03057600 (accessed on 15 February 2021).

18. Bennett, M.K.; Gross, M.I.; Bromley, S.D.; Li, J.; Chen, L.; Goyal, B.; Laidig, G.; Stanton, T.F.; Sjogren, E.B.; Calithera Biosciences, Inc. Treatment of Cancer with Heterocyclic Inhibitors of Glutaminase. International Publication No. WO2014/089048 Al, International Application No. PCT/US2013/072830, 12 June 2014.

19. Gross, M.I.; Demo, S.D.; Dennison, J.B.; Chen, L.; Chernov-Rogan, T.; Goyal, B.; Janes, J.R.; Laidig, G.J.; Lewis, E.R.; Li, J.; et al. Antitumor Activity of the Glutaminase Inhibitor CB-839 in Triple-Negative Breast Cancer. Mol. Cancer Ther. 2014, 13, 890-901. [CrossRef]

20. Restall, I.J.; Cseh, O.; Richards, L.M.; Pugh, T.J.; Luchman, H.A.; Weiss, S. Brain Tumor Stem Cell Dependence on Glutaminase Reveals a Metabolic Vulnerability through the Amino Acid Deprivation Response Pathway. Cancer Res. 2020, 80, 5478-5490. [CrossRef] [PubMed]

21. Kahlert, U.D.; Cheng, M.; Koch, K.; Marchionni, L.; Fan, X.; Raabe, E.H.; Maciaczyk, J.; Glunde, K.; Eberhart, C.G. Alterations in cellular metabolome after pharmacological inhibition of Notch in glioblastoma cells. Int. J. Cancer 2016, 138, 1246-1255. [CrossRef] [PubMed]

22. Koch, K.; Hartmann, R.; Tsiampali, J.; Uhlmann, C.; Nickel, A.-C.; He, X.; Kamp, M.; Sabel, M.; Barker, R.; Steiger, H.-J.; et al. A comparative pharmaco-metabolomic study of glutaminase inhibitors in glioma stem-like cells confirms biological effectiveness but reveals differences in target-specificity. Cell Death Discov. 2020, 6, 20. [CrossRef]

23. Hu, X.; Zhang, Y.; Ding, T.; Liu, J.; Zhao, H. Multifunctional Gold Nanoparticles: A Novel Nanomaterial for Various Medical Applications and Biological Activities. Front. Bioeng. Biotechnol. 2020. [CrossRef]

24. Maeda, H.; Nakamura, H.; Fang, J. The EPR effect for macromolecular drug delivery to solid tumors: Improvement of tumor uptake, lowering of systemic toxicity, and distinct tumor imaging in vivo. Adv. Drug Deliv. Rev. 2013, 65, 71-79. [CrossRef]

25. Giesen, B.; Nickel, A.-C.; Garzón-Manjón, A.; Vargas-Toscano, A.; Scheu, C.; Kahlert, U.D.; Janiak, C. Influence of synthesis methods on the internalization of fluorescent gold nanoparticles into glioblastoma stem-like cells. J. Inorg. Biochem. 2020, 203, 110952. [CrossRef] [PubMed]

26. Zimmermann, S.C.; Wolf, E.F.; Luu, A.; Thomas, A.G.; Stathis, M.; Poore, B.; Nguyen, C.; Le, A.; Rojas, C.; Slusher, B.S.; et al. Allosteric Glutaminase Inhibitors Based on a 1,4-Di(5-amino-1,3,4-thiadiazol-2-yl)butane Scaffold. ACS Med. Chem. Lett. 2016, 7, 520-524. [CrossRef] [PubMed]

27. Mao, W.; Kim, H.S.; Son, Y.J.; Kim, S.R.; Yoo, H.S. Doxorubicin encapsulated clicked gold nanoparticle clusters exhibiting tumor-specific disassembly for enhanced tumor localization and computerized tomographic imaging. J. Control. Release 2018, 269, 52-62. [CrossRef]

28. Ruan, S.; Yuan, M.; Zhang, L.; Hu, G.; Chen, J.; Cun, X.; Zhang, Q.; Yang, Y.; He, Q.; Gao, H. Tumor microenvironment sensitive doxorubicin delivery and release to glioma using angiopep-2 decorated gold nanoparticles. Biomaterials 2015, 37, 425-435. [CrossRef] [PubMed] 
29. Fu, Y.; Feng, Q.; Chen, Y.; Shen, Y.; Su, Q.; Zhang, Y.; Zhou, X.; Cheng, Y. Comparison of Two Approaches for the Attachment of a Drug to Gold Nanoparticles and Their Anticancer Activities. Mol. Pharm. 2016, 13, 3308-3317. [CrossRef]

30. Zhao, H.; Lin, Z.Y.; Yildirimer, L.; Dhinakar, A.; Zhao, X.; Wu, J. Polymer-based nanoparticles for protein delivery: Design, strategies and applications. J. Mater. Chem. B 2016, 4, 4060-4071. [CrossRef]

31. Qin, X.; Li, Y. Strategies to Design and Synthesize Polymer-Based Stimuli-Responsive Drug-Delivery Nanosystems. ChemBioChem 2020, 21, 1236-1253. [CrossRef]

32. Negron, K.; Khalasawi, N.; Lu, B.; Ho, C.-Y.; Lee, J.; Shenoy, S.; Mao, H.-Q.; Wang, T.-H.; Hanes, J.; Suk, J.S. Widespread gene transfer to malignant gliomas with In vitro-to-In vivo correlation. J. Control. Release 2019, 303, 1-11. [CrossRef] [PubMed]

33. Lee, J.M.; Mhawech-Fauceglia, P.; Lee, N.; Parsanian, L.C.; Lin, Y.G.; Gayther, S.A.; Lawrenson, K. A three-dimensional microenvironment alters protein expression and chemosensitivity of epithelial ovarian cancer cells in vitro. Lab. Investig. 2013, 93, 528-542.

34. Kang, M.S.; Lee, S.Y.; Kim, K.S.; Han, D.-W. State of the Art Biocompatible Gold Nanoparticles for Cancer Theragnosis. Pharmaceutics 2020, 12, 701. [CrossRef] [PubMed]

35. Zhang, X.D.; Wu, D.; Shen, X.; Liu, P.X.; Yang, N.; Zhao, B.; Zhang, H.; Sun, Y.M.; Zhang, L.A.; Fan, F.Y. Size-dependent in vivo toxicity of PEG-coated gold nanoparticles. Int. J. Nanomed. 2011, 6, 2071-2081. [CrossRef]

36. Paradossi, G.; Cavalieri, F.; Chiessi, E.; Spagnoli, C.; Cowman, M.K. Poly(vinyl alcohol) as versatile biomaterial for potential biomedical applications. J. Mater. Sci. Mater. Med. 2003, 14, 687-691. [CrossRef] [PubMed]

37. Acharya, A.P.; Chan, S.Y.W.; Little, S.R.; University of Pittsburgh of the Commonwealth System of Higher Education. Compositions and Methods for Administering a YAP1/WWRT1 Inhibiting Composition and a GLS1 Inhibiting Composition. International Publication No. WO2019/104038 Al, International Application No. PCT/US2018/062013, 31 May 2019.

38. Ruan, B.; Ruan, J. Faming Zhuanli Shenqing. Liposome containing glutamine metabolism inhibitor and pharmaceutical composition and use thereof. Patent No. CN107714650, 23 February 2018.

39. Adewale, O.B.; Davids, H.; Cairncross, L.; Roux, S. Toxicological Behavior of Gold Nanoparticles on Various Models: Influence of Physicochemical Properties and Other Factors. Int. J. Toxicol. 2019, 38, 357-384. [CrossRef] [PubMed]

40. Sanabria, N.M.; Gulumian, M. The presence of residual gold nanoparticles in samples interferes with the RT-qPCR assay used for gene expression profiling. J. Nanobiotechnol. 2017, 15, 1-26. [CrossRef]

41. Ponti, J.; Kinsner-Ovaskainen, A.; Norlen, H.; Altmeyer, S.; Cristina, A.; Bogni, A. Interlaboratory Comparison Study of the Colony Forming Efficiency Assay for Assessing Cytotoxicity of Nanomaterials. EUR-Scientific and Technical Research Reports; Report No. 978-92-79-44677-1; Publications Office of the European Union: Luxembourg, 2014.

42. Ernst Ruska-Centre for Microscopy and Spectroscopy with Electrons. FEI Tecnai G2 F20. J. Large-Scale Res. Facil. 2016, 2, 77. [CrossRef]

43. Kahlert, U.D.; Suwala, A.K.; Raabe, E.H.; Siebzehnrubl, F.A.; Suarez, M.J.; Orr, B.A.; Bar, E.E.; Maciaczyk, J.; Eberhart, C.G. ZEB1 promotes invasion in human fetal neural stem cells and hypoxic glioma neurospheres. Brain Pathol. 2015, 25, 724-732. [CrossRef] [PubMed]

44. Liston, D.R.; Davis, M. Clinically Relevant Concentrations of Anticancer Drugs: A Guide for Nonclinical Studies. Clin. Cancer Res. 2017, 23, 3489-3498. [CrossRef]

45. Tsiampali, J.; Neumann, S.; Giesen, B.; Koch, K.; Maciaczyk, D.; Janiak, C.; Hänggi, D.; Maciaczyk, J. Enzymatic Activity of CD73 Modulates Invasion of Gliomas via Epithelial-Mesenchymal Transition-Like Reprogramming. Pharmaceutics 2020, 13, 378. [CrossRef]

46. Turkevich, J.; Stevenson, P.C.; Hillier, J. A study of the nucleation and growth processes in the synthesis of colloidal gold. Discuss. Faraday Soc. 1951, 11, 55-75. [CrossRef]

47. Zhang, H.; Ren, P.; Yang, F.; Chen, J.; Wang, C.; Zhou, Y.; Fu, J. Biomimetic epidermal sensors assembled from polydopaminemodified reduced graphene oxide/polyvinyl alcohol hydrogels for the real-time monitoring of human motions. J. Mater. Chem. $B$ 2020, 8, 10549. [CrossRef]

48. McHugh, K.; Jing, L.; Severt, S.Y.; Cruz, M.; Sarmadi, M.; Jayawardena, H.S.N.; Perkinson, C.F.; Larusson, F.; Rose, S.; Tomasic, S.; et al. Biocompatible near- infrared quantum dots delivered to the skin by microneedle patches record vaccination. Sci. Transl. Med. 2019, 11, e7162. [CrossRef] [PubMed]

49. Huang, Q.; Stalnecker, C.; Zhang, C.; McDermott, L.A.; Iyer, P.; O’Neill, J.; Reimer, S.; Cerione, R.A.; Katt, W.P. Characterization of the interactions of potent allosteric inhibitors with glutaminase C, a key enzyme in cancer cell glutamine metabolism. J. Biol. Chem. 2018, 293, 3535-3545. [CrossRef] [PubMed]

50. Cheng, X.; Tian, X.; Wu, A.; Li, J.; Tian, J.; Chong, Y.; Chai, Z.; Zhao, Y.; Chen, C.; Ge, C. Protein Corona Influences Cellular Uptake of Gold Nanoparticles by Phagocytic; Nonphagocytic Cells in a Size-Dependent Manner. ACS Appl. Mater. Interfaces 2015, 7, 20568-20575. [CrossRef] [PubMed]

51. Larsson, P.; Engqvist, H.; Biermann, J.; Rönnerman, E.W.; Forssell-Aronsson, E.; Kovács, A.; Karlsson, P.; Helou, K.; Parris, T.Z. Optimization of cell viability assays to improve replicability and reproducibility of cancer drug sensitivity screens. Sci. Rep. 2020, 10, 5798. [CrossRef] [PubMed]

52. Elgogary, A.; Xu, Q.; Poore, B.; Alt, J.; Zimmermann, S.C.; Zhao, L.; Fu, J.; Chen, B.; Xia, S.; Liu, Y.; et al. Combination therapy with BPTES nanoparticles and metformin targets the metabolic heterogeneity of pancreatic cancer. Proc. Natl. Acad. Sci. USA 2016, 113, e5328-e5336. [CrossRef] [PubMed] 
53. Fischer, I.; Nickel, A.-C.; Qin, N.; Taban, K.; Pauck, D.; Steiger, H.-J.; Kamp, M.; Muhammad, S.; Hänggi, D.; Fritsche, E.; et al. Different Calculation Strategies Are Congruent in Determining Chemotherapy Resistance of Brain Tumors In Vitro. Cells 2020, 9, 2689. [CrossRef]

54. Khadka, S.; Arthur, K.; Washington, M.; Barekatain, Y.; Ackroyd, J.; Behr, E.; Suriyamongkol, P.; Lin, Y.-H.; Crowley, K.; Pham, C.D.; et al. Impaired Anaplerosis Is a Major Contributor to Glycolysis Inhibitor Toxicity in Glioma. PREPRINT 2020. [CrossRef]

55. Sokolova, V.; Mekky, G.; Van der Meer, S.B.; Seeds, M.C.; Atala, A.J.; Epple, M. Transport of ultrasmall gold nanoparticles (2 nm) across the blood-brain barrier in a six-cell brain spheroid model. Sci. Rep. 2020, 10, 18033. [CrossRef]

56. Khongkow, M.; Yata, T.; Boonrungsiman, S.; Ruktanonchai, U.R.; Graham, D.; Namdee, K. Surface modification of gold nanoparticles with neuron-targeted exosome for enhanced blood-brain barrier penetration. Sci. Rep. 2019, 9, 8278. [CrossRef] [PubMed]

57. Cheng, Y.; Dai, Q.; Morshed, R.A.; Fan, X.; Wegscheid, M.L.; Wainwright, D.A.; Han, Y.; Zhang, L.; Auffinger, B.; Tobias, A.L.; et al. Blood-brain barrier permeable gold nanoparticles: An efficient delivery plat-form for enhanced malignant glioma therapy and imaging. Small 2014, 10, 5137-5150. [CrossRef]

58. Sheleg, S.V.; Korotkevich, E.A.; Zhavrid, E.A.; Muravskaya, G.V.; Smeyanovich, A.F.; Shanko, Y.G.; Yurkshtovich, T.L.; Bychkovsky, P.B.; Belyaev, S.A. Local chemotherapy with cisplatin-depot for glioblastoma multiforme. J. Neurooncol. 2002, 60, 53-59. [CrossRef] [PubMed]

59. Nam, L.; Coll, C.; Erthal, L.C.S.; de la Torre, C.; Serrano, D.; Martínez-Máñez, R.; Santos-Martínez, M.J.; Ruiz-Hernández, E. Drug Delivery Nanosystems for the Localized Treatment of Glioblastoma Multiforme. Materials 2018, 11, 779. [CrossRef]

60. Lenting, K.; Verhaak, R.; Ter Laan, M.; Wesseling, P.; Leenders, W. Glioma: Experimental models and reality. Acta Neuropathol. 2017, 133, 263-282. [CrossRef]

61. Huszthy, P.C.; Daphu, I.; Niclou, S.P.; Stieber, D.; Nigro, J.M.; Sakariassen, P.; Miletic, H.; Thorsen, F.; Bjerkvig, R. In vivo models of primary brain tumors: Pitfalls and perspectives. Neuro. Oncol. 2012, 14, 979-993. [CrossRef] [PubMed]

62. Robertson, F.L.; Marqués-Torrejón, M.A.; Morrison, G.M.; Pollard, S.M. Experimental models and tools to tackle glioblastoma. Dis. Models Mech. 2019, 12. [CrossRef] [PubMed]

63. Upadhyay, U.M.; Tyler, B.; Patta, Y.; Wicks, R.; Spencer, K.; Scott, A.; Masi, B.; Hwang, L.; Grossman, R.; Cima, M.; et al Intracranial microcapsule chemotherapy delivery for the localized treatment of rodent metastatic breast adenocarcinoma in the brain. Proc. Natl. Acad. Sci. USA 2014, 111, 16071-16076. [CrossRef]

64. Semenkow, S.; Li, S.; Kahlert, U.D.; Raabe, E.H.; Xu, J.; Arnold, A.; Janowski, M.; Oh, B.C.; Brandacher, G.; Bulte, J.W.M.; et al. An immunocompetent mouse model of human glioblastoma. Oncotarget 2017, 8, 61072-61082. [CrossRef]

65. Lan, X.; Kedziorek, D.A.; Chu, C.; Jablonska, A.; Li, S.; Kai, M.; Liang, Y.; Janowski, M.; Walczak, P. Modeling human pediatric and adult gliomas in immunocompetent mice through costimulatory blockade. Oncoimmunology 2020, 9, 1776577. [CrossRef] [PubMed]

66. Wei, S.-C.; Hsu, P.-H.; Lee, Y.-F.; Lin, Y.-W.; Huang, C.-C. Selective Detection of Iodide and Cyanide Anions Using GoldNanoparticle-Based Fluorescent Probes. ACS Appl. Mater. Interfaces 2012, 4, 2652-2658. [CrossRef]

67. Zhao, P.; Li, N.; Astruc, D. State of the art in gold nanoparticle synthesis. Coord. Chem. Rev. 2013, 257, 638-665. [CrossRef]

68. Boles, M.; Ling, D.; Hyeon, T.; Talapin, D.V. The surface science of nanocrystals. Nat. Mater. 2016, 15, 141-153. [CrossRef] [PubMed]

69. Xue, Y.; Li, X.; Li, H.; Zhang, W. Quantifying thiol-gold interactions towards the efficient strength control. Nat. Commun. 2014, 5, 4348. [CrossRef] [PubMed]

70. Wang, S.; Wang, X.; Zhang, Z.; Chen, L. Highly sensitive fluorescence detection of copper ion based on its catalytic oxidation to cysteine indicated by fluorescein isothiocyanate functionalized gold nanoparticles. Colloids Surf. A Physicochem. Eng. Asp. 2015, 468, 333-338. [CrossRef]

71. Donahue, N.D.; Acar, H.; Wilhelm, S. Concepts of nanoparticle cellular uptake, intracellular trafficking, and kinetics in nanomedicine. Adv. Drug Deliv. Rev. 2019, 143, 68-96. [CrossRef] [PubMed] 